|IIIIIIIIIIIIIIIIIIIIIIIIIIIIIIIIIII

Technical Report

IIIIIIIIIIIIIIIIIIIIIIIIIIIIIIIIIIII

\title{
Direct effects of insecticides on common ragweed-implications for natural enemy exclusion trials
}

\author{
Suzanne T. E. Lommen, ${ }^{1, *}$ Silvia Fogliatto, ${ }^{2}$ Francesco Vidotto, ${ }^{2}$ Sandra Citterio, ${ }^{3}$ \\ Benno A Augustinus ${ }^{1,4}$ and Heinz MÜLLER-SCHÄRER ${ }^{1}$ \\ ${ }^{1}$ Department of Biology, University of Fribourg, Chemin du Musée 10, 1700 Fribourg, Switzerland \\ ${ }^{2}$ Dipartimento di Scienze Agrarie, Forestali e Alimentari, Università di Torino, \\ Largo Braccini 2, 10095 Grugliasco (TO), Italy \\ ${ }^{3}$ Dipartimento di Science Ambientali, Università di Milano-Bicocca, Piazza della Scienza 1, 20126 Milano, Italy \\ ${ }^{4}$ CABI Europe-Switzerland, Rue des Grillons 1, 2800 Delémont, Switzerland
}

(Received July 20, 2017; Accepted October 15, 2017)

\begin{abstract}
Experimentally applying pesticides is an important method to assess the efficacy of weed biocontrol agents, but potential direct effects of the chemicals on plant performance are controversial or unknown. We assessed how three broad-spectrum insecticides applied in combination affect the performance of the widely invasive, crop-yield reducing, allergenic common ragweed (Ambrosia artemisifolia L.) in an insect-free environment. Spraying insecticides had no significant effects on aboveground dry weight, seed and pollen output or pollen allergenicity, and only explained 1-8\% of variation in these parameters. Our insecticide treatment can hence be applied to assess biocontrol impact on biomass and reproductive output of common ragweed. As our insecticide treatment delayed senescence, however, other methods of insect exclusion should be preferred when studying common ragweed phenology. (C) Pesticide Science Society of Japan

Keywords: biological weed control, growth promotor, insect exclusion, invasive plant, plant performance, phytotoxicity.
\end{abstract}

Electronic supplementary material: The online version of this article contains supplementary material (Supplemental Figures S1 and S2), which is available at http://www.jstage.jst.go.jp/browse/jpestics/.

\section{Introduction}

Biological control is an important method to manage noxious plants, as shown by an increasing number of targeted plants and new biocontrol agents released. ${ }^{1)}$ This is especially useful when traditional control methods (e.g., herbicides, cutting) cannot be applied due to environmental or economic constraints, such as in semi-natural habitat types or organic farming and for widely dispersed invasive plants. To test the efficacy of the intended biocontrol agents, the performance of the target plant population is ideally assessed in parallel in the absence and in the presence of these antagonists. ${ }^{2}$ The application of insecticides is one frequently used method to eliminate insects in order to assess the efficacy of the natural insect community (in conservation biocontrol), or the augmented or the introduced insects (in augmentative and classical biocontrol, respectively). ${ }^{3,4)}$ The underlying assumption is that insecticides have no direct effects on the plants. This should, however, be tested for the specific system

\footnotetext{
* To whom correspondence should be addressed.

E-mail: suzannelommen@hotmail.com

Published online December 22, 2017

(c) Pesticide Science Society of Japan
}

under study, since literature dealing with direct interactions between insecticides and plant performance are scarce, and so far published results report mixed effects.

Plants can be negatively affected in their growth by insecticides through phytotoxicity or interference with the plants' physiology causing growth inhibition, precocious tissue differentiation, and flower abortion. ${ }^{5)}$ For example, the application of phorate reduced root and shoot growth and yield of tomato and pearl millet. ${ }^{6}$ 7) Some organophosphate insecticides such as dimethoate and chlorpyriphos also caused phytotoxicity to several (non-target) weed species (i.e., annual forbs, Poa spp.), in particular by inhibiting or slowing weed seed germination. ${ }^{8)}$ Other studies, in contrast, found positive effects of insecticides through enhanced root development, plant growth, or physiological activity, sometimes resulting in increased yield. ${ }^{9,}$ 10) The application of carbofuran, a systemic carbamate, increased yields and biomass of several crops including watermelon, pea, tobacco and corn, because the metabolites of this molecule promoted crop growth and inhibited the activity of indole acetic acid oxidase. ${ }^{5}$ ) Treatments with chlordimeform, a formamidine insecticide, and imidacloprid, a neonicotinoid insecticide had similar positive direct effects on cotton growth. ${ }^{11}{ }^{12)}$ Other molecules did not show any effect on tested crops, such as flonicamid applied 
to okra. ${ }^{13)}$ The specific effect, therefore, likely depends both on the insecticide class applied and the treated plant species. ${ }^{9)}$ This highlights the relevance of assessing these effects when using insecticides in insect-exclusion studies, especially when the experimental frequency of application is higher than when applied to crops.

We used three broad-spectrum insecticides in exclusion experiments in natural populations of the invasive common ragweed, Ambrosia artemisiifolia L. (Asteraceae), in northern Italy, to assess the potential impact of the accidentally established ragweed leaf beetle Ophraella communa L. (Chrysomelidae). ${ }^{14)}$ Common ragweed originates from central USA where it is a major weed of field crops. ${ }^{15)}$ It has become invasive on many other continents, ${ }^{16)}$ causing crop yield reductions (overview for Europe $\mathrm{in}^{17)}$ ) and producing allergenic pollen that have increased allergenicity-related symptoms in human populations. ${ }^{18)}$ Ophraella communa is a candidate biocontrol agent which has already proven successful in reducing common ragweed densities after mass-release in crop fields in Canada, ${ }^{19)}$ and more recently in an inoculative approach in ruderal areas in China where the species had earlier been accidentally introduced. ${ }^{20-22)}$ The beetle has also accidentally been introduced into Japan, where it feeds on several invasive species of Ambrosia. ${ }^{23)}$ Assessments of its potential impact in Europe have been prioritized. ${ }^{24}$

It is unknown how insecticides affect common ragweed performance or the allergenicity of its pollen. The allergenicity of pollen of this species is known to be altered by other abiotic stressors, such as drought, aerial pollutants and elevated levels of $\mathrm{CO}_{2}, \mathrm{NO}_{2}$ and $\mathrm{O}_{3} \cdot{ }^{25-29)}$ We therefore specifically tested whether the application of the three selected broad-spectrum insecticides has direct effects on i) plant traits, ii) seed and pollen numbers, and iii) the allergenicity of pollen of common ragweed.

\section{Materials and Methods}

\section{Selection of insecticides and application design}

Since no insecticide is used specifically against our target species $O$. communa, we chose broad-spectrum pesticides widely applied in crops or horticulture. Neonicotinoids are systemic insecticides that have become the most used class of insecticides worldwide. ${ }^{30,31)}$ Their translaminar activity acts as agonist on nAChRs opening cation channels inducing excitation of the neuronal membranes, causing paralyses. We selected acetamiprid (Epik ${ }^{\circledR}, 5 \mathrm{~g}$ ai $100 \mathrm{~g}^{-1}$, SIPCAM, via Sempione 195, 20016 Pero, Italy), which is one of the most used neonicotinoids and applied on about 60 crops. We applied this every four weeks, and due to its long-lasting activity in the plant, it hence provided continuous protection. Insects sequester the chemical by feeding on the plant, but since the substance is only toxic at high doses, it does not provide instantaneous control. Some studies have reported positive effects (increased plant height and flowering, enhanced seed vigor, and higher chlorophyll content) as well as negative effects (lower total soluble protein) on treated corn plants, while others found no effects on treated plants. ${ }^{32)}$

To complement the systemic insecticide we selected two con- tact insecticides to instantaneously suppress high densities of insects that can occur in the field (e.g. through immigration of adults). Pyrethroids are synthetic analogous of pyrethrins that affect insect nerve fibers. This class of insecticides has been widely used since 1970 to control a wide spectrum of agricultural and public health pests, such as thrips, aphids, beetles, flies, mosquitos and beetles. ${ }^{30,33)}$ We chose deltamethrin (Decis ${ }^{\circledR}$ Evo, $2.42 \mathrm{~g}$ ai $100 \mathrm{~g}^{-1}$, Bayer CropScience Italia, Viale Certosa 130, 20156 Milan, Italy) and lambda-cyhalothrin (Karate ${ }^{\circledR}$ Zeon 1.5, $1.47 \mathrm{~g}$ ai $100 \mathrm{~g}^{-1}$, Syngenta Italia, Via Gallarate 139, 20151 Milan, Italy), two of the most widely used pyrethroids. ${ }^{30)}$ Deltamethrin was reported to have negative effects on the growth of maize compared to untreated plants, ${ }^{34)}$ but no such effects are known for lambda-cyhalothrin. As adults of the targeted biocontrol agent are highly mobile, they can easily move between ragweed populations. We therefore chose a biweekly (thus frequent) application of contact insecticides, but alternated the two chemicals to reduce the development of resistance.

\section{Experimental design}

Seeds were originally collected from about 30 plants from a natural population of common ragweed along the roadsides at the campus of DISAFA in Grugliasco, Italy in 2014, and were stored under dry and cool conditions. In mid May 2016, pots with $1 \mathrm{~L}$ of local silt-loam soil were sown with five of these seeds each in a greenhouse, and emerged seedlings were thinned to one seedling per pot after 2 weeks. The experiment commenced when seedlings had developed four true leaves and were $c a .5 \mathrm{~cm}$ tall. Half of a total of 72 undamaged potted seedlings was randomly picked and assigned to the control treatment, while the rest was assigned to the insecticide treatment. Pots were arranged in trays, such that each tray contained three pots of the same treatment (i.e., 12 trays $\times 3$ plants per treatment). The 24 trays were then randomly placed in the centre of an insect-free experimental mesh cage of $2 \mathrm{~m}$ by $2 \mathrm{~m}$ by $2 \mathrm{~m}$ outdoors at the same campus, and were surrounded by a line of potted common ragweed plants serving as a buffer (Supplemental Fig. S1). The maximum height and largest diameter of each experimental seedling was recorded prior to the treatment application.

All experimental plants were treated biweekly by spraying the trays with an equivalent of $1000 \mathrm{~L} \mathrm{ha}^{-1}$ outside the cage. In the insecticide treatment we alternated a mix of acetamiprid ( $100 \mathrm{~g}$ ai ha $\left.\mathrm{h}^{-1}\right)$ and deltamethrin $\left(20 \mathrm{~g}\right.$ ai ha $\left.{ }^{-1}\right)$ with lambda-cyhalothrin $\left(20 \mathrm{~g}\right.$ ai ha ${ }^{-1}$ ) only (doses corresponded to the maximum amount allowed in crops or horticultural products). The control plants were sprayed with an equal amount of water. To avoid microclimatic effects, we randomly changed the position of the trays within the cage after each application. A total of 6 applications was made.

At the end of August, when male flowers were flowering, we collected mature pollen in Eppendorf tubes by gently tapping the racemes (Supplemental Fig. S2). Because pollen of individual plants was often insufficient for analyses and could not always be collected separately, we pooled pollen from the three plants per 
tray (i.e., 12 tubes per treatment). To assess the allergenicity of the pollen samples, we evaluated the immunoreactivity of pollen extracts to a pool of sera from ragweed allergic patients ${ }^{35)}$ using a slot-blot technique. For each pollen sample, four subsamples of $5 \mu \mathrm{L}$ were taken, and their reactivity signal was determined with image analyses by the integrated optical density (IOD) of the immunoreactive spots relative to the IOD of a standard protein extract from commercial ragweed pollen (Allergon ${ }^{\circledR}$, Allergon Thermo Fisher Scientific, Välingevägen 309 SE-262 92 Ängelholm, Sweden).

Treatments continued until the plants had set seed in September. At that moment, we assessed individual plants for survival, senescence and damage, recorded again their maximum height and width, measured the total length of the racemes (a proxy for the amount of pollen produced), and counted individual seeds (including flowers and unripe seeds). We then harvested the above-ground biomass of each plant and determined its dry weight.

\section{Statistics}

We assessed the effect of treatment on log-transformed dry weight, number of seeds and total raceme length by linear mixed effect models using log-transformed initial volume of the seedling (calculated as volume $=$ height $\left.\times \pi \times(0.25 \times \text { width })^{2}\right)$ as a covariate and tray as a random effect. For each response variable we created a set of models including all relevant combinations of treatment, seedling volume and their interaction, or no factor (the null-model) as fixed effects, and fitted them with Maximum Likelihood to allow model comparison. We then selected a subset of credible models based on the values of the conditional Akaike Information Criterion (AICc). We always selected the model with the lowest AICc value (the "best" model), and subsequently included models with higher AIC values up to a difference of 6 compared to the best model $^{36)}$ if these had fewer parameters (consistent with the principle of parsimony). This subset was used to create a weighted average model, whose factors were considered significant if the $95 \%$ confidence interval of their parameter estimates did not overlap zero. As the random effect of tray never explained a significant amount of variation, the proportion of variance explained by the treatment was then calculated by an Analysis of Variance (ANOVA) with treatment and seedling volume as fixed factors. To test differences in allergenicity between the treatments, we applied a $t$-test on the average IOD per pollen sample (average of the four subsamples), assuming unequal variance and applying a Welsh modification. All statistical analyses were performed using R 3.3.1. ${ }^{37)}$

\section{Results}

All 72 plants survived until after reproduction and showed no signs of feeding damage, but 12 of the 36 control plants from 6 different trays had already senesced at the time of the measurement and had dried out. All models of plant dry weight were regarded credible (Table 1), and the resulting average model (Table 2) revealed that none of the factors had a significant effect on
Table 1. The subset of credible models for plant dry weight with their degrees of freedom (df), ranked by their conditional Akaike Information Criterion (AICc), the difference with the AIC of the best model in this subset $(\triangle \mathrm{AICc})$ and their weight.

\begin{tabular}{lcccc}
\hline \multicolumn{1}{c}{ Fixed effects of models } & df & AICc & $\Delta$ AICc & Weight \\
\hline Treatment $\times \log$ (seedling volume) & 6 & 79.9 & 0.00 & 0.284 \\
Treatment+ $\log$ (seedling volume) & 5 & 80.2 & 0.24 & 0.252 \\
Treatment & 4 & 80.3 & 0.33 & 0.241 \\
Log (seedling volume) & 4 & 81.6 & 1.69 & 0.122 \\
- (null model without fixed effects) & 3 & 82.0 & 2.08 & 0.101 \\
\hline
\end{tabular}

plant dry weight. Overall there was large unexplained variance among the weights of individual plants (Fig. 1A), and treatment only explained $8.0 \%$ of all variation in the ANOVA. For both raceme length (Fig. 1B) and numbers of seeds (Fig. 1C), the null-model was best. Again most variation was found between individual plants and treatment only explained $1.3 \%$ and $1.2 \%$ in the corresponding ANOVAs, respectively. We found no significant difference in allergenicity between treatments (also not in a mixed model with treatment as fixed effect and subsample as random effect), even though the variation and mean seemed larger in the insecticide-treated samples (Fig. 2).

\section{Discussion}

Successful biological control of $A$. artemisiffolia reduces the production of seeds and pollen, without increasing allergenicity of the pollen. The application of our insecticide treatment, constituting the alternation of three different broad-spectrum compounds, resulted in negligible effects on plant dry weight, raceme length, seed production (Fig. 1), and pollen allergenicity (Fig. 2). This is due to the large amount of unexplained variation among individual plants. It seems typical of $A$. artemisiifolia that individual plant identity explains most of the variation in the traits of plants ${ }^{38)}$ and pollen ${ }^{39)}$ even under standardized conditions. This highlights the relevance of genetic, epigenetic, or maternal effects in determining the traits of plants and pollen in this species. Ambrosia artemisiifolia is known to have large intraspecific genetic variation, likely due to its reproductive system of wind-pollination and outcrossing, ${ }^{15)}$ and the admixture of populations before their invasion. ${ }^{40)}$ Under natural field conditions even more variation in phenotypic traits can be expected because of local environmental variation and the huge phenotypic plasticity of the species. It is, therefore, unlikely that insecticides will result in detectable direct effects in the investigated

Table 2. The parameters of the average model for log-transformed plant dry weight, with their estimate, adjusted standard error, and 95\% confidence interval of the estimates.

\begin{tabular}{lrcc}
\hline \multicolumn{1}{c}{ Parameter } & Estimate & Adjusted SE & \multicolumn{1}{c}{$95 \%$ CI } \\
\hline (Intercept) & 0.759 & 0.449 & $-0.121-1.639$ \\
Log(seedling volume) & 0.123 & 0.136 & $-0.143-0.389$ \\
Treatment & 0.405 & 0.488 & $-0.551-1.361$ \\
Treatment: $\log$ (seedling volume) & -0.071 & 0.139 & $-0.342-0.201$ \\
\hline
\end{tabular}



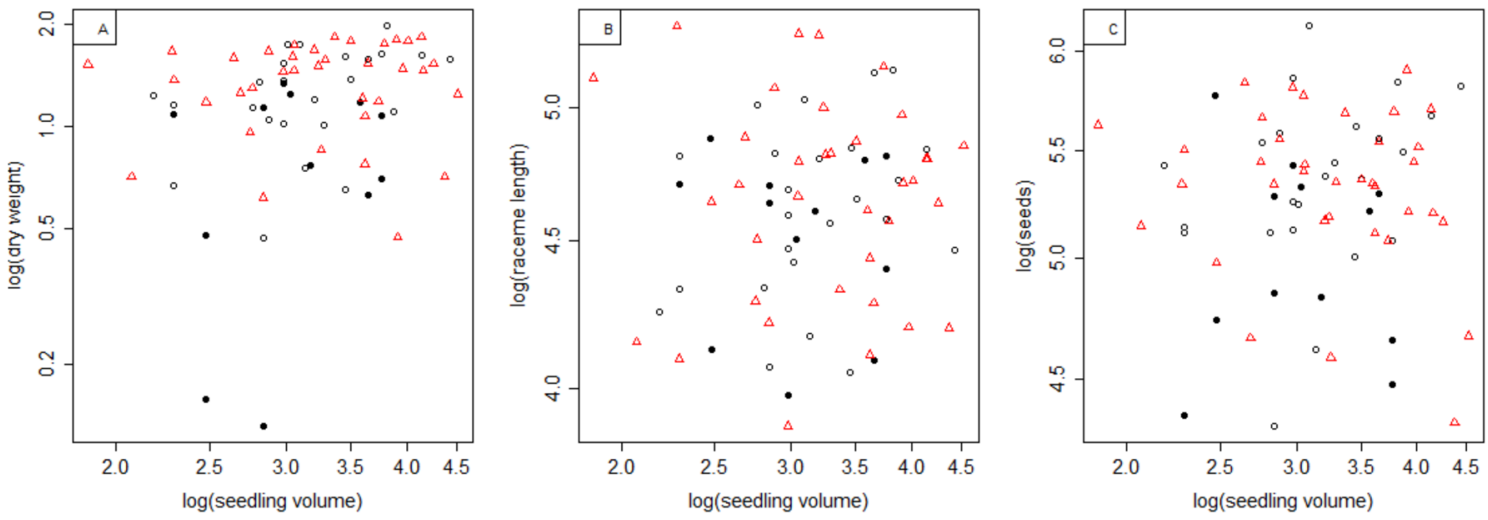

Fig. 1. The effects of the insecticide treatment and seedling volume on the dry weight (A), raceme length (B), and number of seeds (C) of common ragweed, all at a log-log-scale. Circles represent plants of control treatments (open circles for vital plants, closed circles for those already senesced at the time of measurement), while triangles represent plants subjected to the insecticides treatment. No significant effects of treatment or seedling volume were found for any of the response variables.

traits under natural conditions. In addition, effects of any successful biocontrol agent should be much larger. Therefore, our treatment can safely be applied to assess the impact of an insect agents when results are compared to controls not treated with insecticides.

One should take into consideration, however, that such broad-spectrum insecticides as used in our experiment eliminate the entire insect community and may therefore not reflect the effect of the biocontrol agent alone. In our case study this posed no problem since $O$. communa was always largely outnumbering the very few other insects sometimes found on the plants, and leaf-feeding damage resulting from other insects was never observed (Lommen, unpublished results).

We detected delayed plant senescence as a response to the insecticide treatment. This may be the result of slower or prolonged growth. The observation that the senesced plants tended to have smaller weights than still vital plants (Fig. 1A), renders

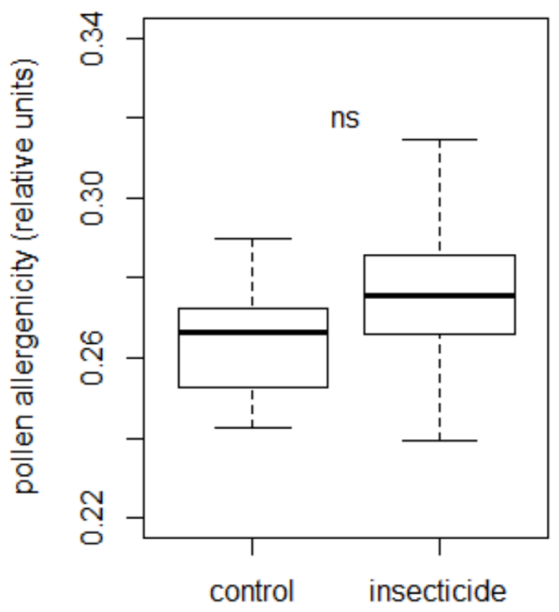

Fig. 2. The effect of the insecticide treatment on common ragweed pollen allergenicity, assessed by a Slot-blot technique followed by image analysis of the optical density, relative to a standard. The "ns" indicates no significant difference between the means of the two treatments. the mechanism of prolonged growth more likely. These results imply that studies on plant phenology should utilize other methods of insect exclusion. ${ }^{4)}$ For instance, when investigating if $O$. communa exerts a selection pressure on the timing of flowering of $A$. artemisiifolia in the wild, which has been found in the laboratory, the use of exclusion cages would be more appropriate. ${ }^{41)}$

Our study does not allow us to disentangle potential effects of the individual chemical compounds on A. artemisiifolia. In corn, acetamiprid has been reported to increase plant height in corn, ${ }^{32)}$ but deltamethrin had negative effects on this crop's growth. ${ }^{34)}$ Unfortunately their joint effect on corn is unknown.

We acknowledge that our conclusions cannot be generalized to other study systems, and we advocate a case-by-case approach as long as general patterns regarding the direct effects of insecticides on plants remain unknown. The documentation of such case studies is important to standardize experimental applications across studies on the same system. This applies to investigating the efficacy of insects for weed biocontrol as well as to studying plant-insect interactions in other contexts, ${ }^{42)}$ allowing comparisons of effects found in different studies. The accumulation of such case studies, ideally replicated in time and space, should aid in building up knowledge about the consistency of chemical effects across different molecules within classes of insecticides on different target plants.

\section{Acknowledgements}

We thank Simon Vandenbrande for help in the development of the insecticide protocol, Tessa Smith for help with the data collection, Dr Riccardo Asero for providing human sera, Dr Maria Guarino for her help in laboratory experiments, and Dr Rudolf Rohr for statistical advice. We acknowledge financial support from the Swiss State Secretariat for Education, Research and Innovation (C13.0146 to HMS and STEL) and the EU COST Action FA1203 'Sustainable management of Ambrosia artemisiifolia in Europe (SMARTER).

\section{References}

1) R. L. Winston, M. Schwarzländer, H. L. Hinz, M. D. Day, M. J. W. 
Cock and M. H. Julien: "Biological Control of Weeds: a World Catalogue of Agents and Their Target Weeds," USDA Forest Service, Forest Health Technology Enterprise Team, Morgantown, West Virginia, 2014.

2) L. Morin, A. M. Reid, N. M. Sims-Chilton, Y. M. Buckley, K. Dhileepan, G. T. Hastwell, T. L. Nordblom and S. Raghu: Biol. Control 51, $1-15$ (2009).

3) R. E. C. McFadyen: Annu. Rev. Entomol. 43, 369-393 (1998).

4) E. Siemann, W. P. Carson, W. E. Rogers and W. W. Weisser: "Reducing Herbivory Using Insecticides," ed. by W. W. Weisser and E. Siemann, Springer Berlin Heidelberg, Berlin, Heidelberg, pp. 303-327, 2004.

5) R. E. Foster and G. E. Brust: Crop Prot. 14, 619-624 (1995).

6) R. Guedes, N. C. Nelsa, M. P. Guedes and M. Picanço: Anais da Sociedade Entomológica do Brasil 27, 443-449 (1998).

7) C. W. Kennedy: Crop Prot. 21, 799-802 (2002).

8) A. C. Gange, V. K. Brown and L. M. Farmer: J. Appl. Ecol. 29, 303310 (1992).

9) E. P. Lichtenstein, G. T. Cowley and W. F. Millington: J. Agric. Food Chem. 10, 251-256 (1962).

10) G. Preetha and J. Stanley: J. Plant Nutr. 35, 1234-1245 (2012).

11) P. J. Bauer and J. T. Cothren: Agron. J. 82, 73-75 (1990).

12) E. D. Gonias, D. M. Oosterhuis and A. C. Bibi: Amer. J. Plant Sci. Biotech. 2, 60-62 (2008).

13) M. H. Kodandaram, Y. B. Kumar, K. Banerjee, S. Hingmire, A. B. Rai and B. Singh: Crop Prot. 94, 13-19 (2017).

14) H. Müller-Schärer, S. T. E. Lommen, M. Rossinelli, M. Bonini, M. Boriani, G. Bosio and U. Schaffner: Weed Res. 54, 109-119 (2014).

15) I. J. Bassett and C. W. Crompton: Can. J. Plant Sci. 55, 463-476 (1975).

16) F. Essl, K. Biró, D. Brandes, O. Broennimann, J. M. Bullock, D. S. Chapman, B. Chauvel, S. Dullinger, B. Fumanal, A. Guisan, G. Karrer, G. Kazinczi, C. Kueffer, B. Laitung, C. Lavoie, M. Leitner, T. Mang, D. Moser, H. Müller-Schärer, B. Petitpierre, R. Richter, U. Schaffner, M. Smith, U. Starfinger, R. Vautard, G. Vogl, M. von der Lippe and S. Follak: J. Ecol. 103, 1069-1098 (2015).

17) Z. Domonkos, V. Szigeti Szabó, A. Farkas, G. Pinke, P. Reisinger, T. Vereš and P. Tóth: J. Cent. Eur. Agric. 18, 29-41 (2017).

18) G. D’Amato, S. T. Holgate, R. Pawankar, D. K. Ledford, L. Cecchi, M. Al-Ahmad, F. Al-Enezi, S. Al-Muhsen, I. Ansotegui, C. E. BaenaCagnani, et al.: World Allergy Organ. J. 8, 1-52 (2015).

19) M. Teshler, A. DiTommaso, J. Gagnon and A. Watson: "Ambrosia artemisiifolia L., Common Ragweed (Asteraceae)," ed. by P. Mason and J. Huber, CABI Publishing, Wallingford, UK, pp. 290-294, 2002.

20) S. J. Huang, Q. Chen, H. S. Chen, W. J. Qin, X. Q. Tu and J. Y. Guo: J. Biosafety 20, 310-313 (2011).

21) Z. S. Zhou, H. S. Chen, J. Y. Guo, W. Guo, Y. H. Luo, X. W. Zheng, M. Luo, H. Y. Zheng and F. H. Wan: J. Biosafety 20, 186-191 (2011).
22) Z. S. Zhou, H. S. Chen, X. W. Zheng, J. Y. Guo and F. H. Wan: J. Biosafety 20, 267-269 (2011).

23) Y. Fukano and H. Doi: Biocontrol Sci. Technol. 23, 595-601 (2013).

24) S. Lommen, E. Jolidon, J. Bustamante Eduardo and H. Müller-Schärer: Eur. J. Entomol. 114, 160-169 (2017).

25) L. H. Ziska and F. A. Caulfield: Aust. J. Plant Physiol. 27, 893-898 (2000).

26) F. Zhao, A. Elkelish, J. Durner, C. Lindermayr, J. B. Winkler, F. Rueff, H. Behrendt, C. Traidl-Hoffmann, A. Holzinger, W. Kofler, et al.: Plant Cell Environ. 39, 147-164 (2016).

27) F. Zhao, J. Durner, J. B. Winkler, C. Traidl-Hoffmann, T. M. Strom, D. Ernst and U. Frank: Environ. Pollut. 224, 503-514 (2017).

28) A. El Kelish, F. Zhao, W. Heller, J. Durner, J. B. Winkler, H. Behrendt, C. Traidl-Hoffmann, R. Horres, M. Pfeifer, U. Frank and D. Ernst: BMC Plant Biol. 14, 176 (2014).

29) A. Ghiani, S. Ciappetta, R. Gentili, R. Asero and S. Citterio: Sci. Rep. 6, 30438 (2016).

30) K. A. Lewis, J. Tzilivakis, D. J. Warner and A. Green: Hum. Ecol. Risk Assess. 22, 1050-1064 (2016).

31) N. Simon-Delso, V. Amaral-Rogers, L. P. Belzunces, J. M. Bonmatin, M. Chagnon, C. Downs, L. Furlan, D. W. Gibbons, C. Giorio, V. Girolami, D. Goulson, D. P. Kreutzweiser, C. H. Krupke, M. Liess, E. Long, M. McField, P. Mineau, E. A. D. Mitchell, C. A. Morrissey, D. A. Noome, L. Pisa, J. Settele, J. D. Stark, A. Tapparo, H. Van Dyck, J. Van Praagh, J. P. Van der Sluijs, P. R. Whitehorn and M. Wiemers: Environ. Sci. Pollut. Res. 22, 5-34 (2015).

32) B. T. Unal and A. E. Dereboylu: Phyton-Int. J. Exp. Bot. 84, 144-147 (2015).

33) L.-M. He, J. Troiano, A. Wang and K. Goh: "Environmental Chemistry, Ecotoxicity, and Fate of Lambda-Cyhalothrin," ed. by D. M. Whitacre, Springer New York, pp. 71-91, 2008.

34) R. E. Duran, S. Kilic and Y. Coskun: Pestic. Biochem. Physiol. 124, 15-20 (2015).

35) R. Asero, E. Bellotto, A. Ghiani, R. Aina, D. Villalta and S. Citterio: Ann. Allergy Asthma Immunol. 113, 307-313 (2014).

36) S. A. Richards: Ecology 86, 2805-2814 (2005).

37) http://www.R-project.org/ (Accessed: 1 March, 2017).

38) W. Ortmans, G. Mahy, B. Chauvel and A. Monty: Flora 220, 134-141 (2016).

39) S. Lommen, S. Ciappetta, A. Ghiani, R. Asero, R. Gentili, H. MüllerSchärer and S. Citterio: Plant Biosyst. 151, 1094-1100 (2016).

40) M. Gaudeul, T. Giraud, L. Kiss and J. A. Shykoff: PLoS One 6, e17658 (2011).

41) Y. Fukano, K. Tanaka and T. Yahara: Basic Appl. Ecol. 14, 387-395 (2013).

42) S. Rasmann and K. A. Mooney: Curr. Opin. Insect Sci. 14, v-vii (2016). 